\title{
Lipid Lowering Activity of Some Medicinal Plants: A Review of Literature
}

\author{
Reema Srivastava*1 and Pankaj Srivastava ${ }^{2}$ \\ ${ }^{1}$ Department of Botany, Kanoria Mahila Mahavidyalaya, India \\ ${ }^{2}$ Department of Surgery, Om Surgical Center \& Maternity Home, India
}

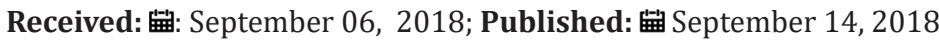

*Corresponding author: Reema Srivastava, Asstt. Professor, Department of Botany, Kanoria PG Mahila Mahavidyalaya, Jaipur, India

\begin{abstract}
When abnormally high levels of lipids (fatty substances) are found in the blood, this condition is known as hyperlipidemia. Obesity is also related to this disorder. Hypolipidemic drugs are extensively used to prevent such disorders, but these drugs have other adverse effects. In India about 150 medicinal plants have been used as herbal drugs against these disorders. This review focused on some medicinal plants which have lipid lowering activities.
\end{abstract}

Keywords: Hyperlipidemia; Medicinal plants; Obesity; Lipid

Abbreviations: CVD: Cardio Vascular Disease; TC: Total Cholesterol; LDL-C: Low Density Lipoprotein Cholesterol; VLDL-C: Very Low-Density Lipoprotein Cholesterol; TAG: Triglycerides; HDL-C: High Density Lipoprotein Cholesterol

\section{Introduction}

Obesity is one of the most common health problems and this disorder is associated with abnormal levels of blood lipids (hyperlipidemia) and lipoproteins (hyperlipoproteinemia). In hyperlipidemic conditions, the levels of lipids and cholesterol elevated in the blood and it is a symptom of different disorders of lipoprotein metabolism [1]. Hyperlipidemia is a condition of excess fatty substances called lipids, largely cholesterol and triglycerides in the blood. The extra amount of lipid circulates in blood attached to the protein and this condition is known as hyperlipoptoteinemia. During the circulation the fatty substances remain dissolved [2]. It is a disorder of lipid metabolism caused by elevation of plasma concentrations of the various lipid and lipoprotein fraction, which are the key risks factors for cardio vascular disease (CVD). It also increases the cholesterol esters, phospholipids or triglycerides. Predisposition to coronary, cerebrovascular and peripheral vascular arterial diseases are the most common reason of death in developing and developed nations and they are mostly due to abnormalities in plasma lipids [3].

Hyperlipidemia, specially characterized by alterations occurred in serum lipid and lipoprotein profile this is because of increased concentrations of TC, LDL-C, VLDL-C, and TAG with a decrease in the concentrations of HDL-C in the blood circulation [4]. The World Health Organization (WHO) has listed 21,000 plants, which are used for medicinal purposes around the world. About 2500 species are present in India and 150 species are used commercially at the large scale. India is the largest producer of medicinal herbs and is called as botanical garden of the world [5]. A healthy diet that includes fruits, vegetables and legumes along with regular exercise program is helpful in cardiovascular diseases [6]. Hence the review study is concluded that the herbal drug possesses antihyperlipidemic activity and it has been proved by different animal models give many links to develop the future trials.

\section{Lagenaria Siceraria [LS]}

Lagenariasiceraria (Cucurbitaceae, common name bottle gourd, lauki), commonly, used for cardiovascular diseases. Fruitscontain cardioprotective, cardiotonic, general tonic, diuretic, and aphrodisiac, antidote activity to certain poisons and scorpion strings, alternative purgative, cooling effectsand fruits also contain the triterpenoid cucurbitacins B, D, G, Hand 22-deoxycucurbitacin. It cures pain, ulcers and fever and used for pectoral-cough, asthma and other bronchial disorders-especially syrup prepared from the tender fruit 1, 2. It contains good amount of minerals and amino acids. The fruit juice contains $\beta$-glycosidase-elasterase enzyme [7-12]. Agarwal et al. [13] reported that the fractions from the methanolic extract of LS fruit had significantly reduced the elevated triglyceride, cholesterol, and LDL and increased HDL level of 
triton treated hyperlipidemic rats. Ghule et al. [14] suggested that hypolipidemic and antihyperlipidemic effects of LSfruit extracts.

Nainwal et al. [15] studied the effect of juice of the fresh fruits of LS on the blood cholesterol level of atherogenic diet rats. The study showed that juice of the fresh fruits of LS have the potential to cause a blood cholesterol lowering effect. The serum biochemistry changes many suggest that the juice extract has a tonic effect on the kidneys and the liver and these organs playcentral role in drug metabolism. Absence of significant lesion in the kidney, liver and testes may indicate that the plant is safe for medicinal use. Mohale et al. [16] also reported that the elevated levels of blood cholesterol, triglycerides, LDL, were significantly reduced and decreased HDL was significantly increased by the administration of fractions of LS fruit juice.

\section{Commiphora wightii [CW]: Syn-Commiphora Mukul}

Guggulu (Commiphora wightii (Arn.) Bhandari) belong to family Burseraceae and it is a popular herb classified as Tridoshahar in Indian Ayurvedic medicine that is used to treat several ailments. History revealed that Guggulu has prime place in Vedas, Samhitas, Nighantus and in Rasa classics [17]. It is used in various disease conditions like Kustha (skin diseases), Medoroga (lipid disorders), Aamavata (rheumatic arthritis), Sandhigata Vata (osteoarthritis), Gulma (Abdominal lump), Shotha (odema) etc [18]. Guggul gum resin is useful for arthritis, lowering high cholesterol, "hardening of the arteries" (atherosclerosis), acne and other skin diseases, and weight loss. GW has a wide range of useful properties in indigenous medicine. The lipid lowering activity of guggulu was first reported as guggulipid [19-21]. The lipid lowering effect of GW with special reference to atherosclerosis and obesity (medoraga) was first reported in a doctorate thesis submitted to the Banaras Hindu University (BHU) in January 1966.

Earlier to this work, GW was well known as an Ayurvedic drug for the treatment of various types of arthritis. In carefully planned studies carried out (over a period of two years) on rabbits, in which hyperlipidemia was induced by feeding cholesterol (in hydrogenated vegetable oil), it was demonstrated for the first time it was reported that in hypercholesterolemic rabbits, guggulu lowers the serum cholesterol and protected these animals from cholesterol induced atherosclerosis. It also reduced the body weight of the animals. Similar results were found in patients with obesity and hypercholesterolemia. The Central Drug Research Institute (CDRI), Lucknow has been engaged in chemical, pharmacological, and clinical studies on guggulu [22]. Gugulipid is an ethyl acetate extract of oleoresin. It was standardized at CDRI and has been marketed in India since 1988, due to its hypolipidemic activities. Gugulipid contain guggusterones which is responsible for guggulu's hypolipidemic activity [23-24].

A number of clinical studies were carried out to confirm hypolipidemicactivity of guggulu and gugulipid [25-26]. The findings of multicentric clinical trials carried out with gugulipid at seven different centers in India coordinated in collaboration with CDRI confirmed the role of gugulipid as a hypolipidemic agent [25]. In various animal models and clinical researches the hypolipidemic activity of guggulu has been studied [27]. In another study, highly significant reduction in levels of mean serum cholesterol and triglyceride was observed in groups of animals receiving high-fat diet for one month along with guggulu, which clearly demonstrated its hypolipidemic activity. Additionally, administration of guggulu partially reversed the atherosclerosis in the aorta that was induced by high-fat diet [28]. Guggulu showed its hypolipidemic effect in clinical studies and the lipid profile has been changed. This study showed significant decrease in total cholesterol and LDL cholesterol after treatment with guggulu [29].

Thyroxin and triiodothyronine hormones enhance the metabolism of carbohydrates and protein synthesis and also help in lowering the lipid activity. Guggulu increases the production of these hormones. The properties of guggulu make it beneficial against atherogenesis. Lipolytic enzymes of plasma and liver activate by gugulipid and it also stimulates catabolism of low density lipoprotein [30-32]. Guggulis possibly safe for most people when taken by mouth appropriately. It has been used safely in clinical trials for upto 24weeks. Some evidence also suggests that longterm use upto 75 weeks may be safe. It can cause side effects such as stomach upset, headaches, nausea, vomiting, loose stools, diarrhea, belching, and hiccups. The lipid lowering action of guggulsterone, the active constituent of guggulipid, has been studied in triton and cholesterol fed hyperlipidemic rats. Serum lipids were found to be lowered by guggulsterone $(50 \mathrm{mg} / \mathrm{kg})$ in triton WR-1339 induced hyperlipidemia. Chronic feeding of this drug ( $5 \mathrm{mg} / \mathrm{kg}$ ) in animals simultaneously fed with cholesterol $(25 \mathrm{mg} / \mathrm{kg})$ for 30 days caused lowering in the lipid and apoprotein levels of very low density and lowdensity lipoproteins in experimental animals [33].

\section{Glycyrriza Glabra (GG)}

Glycyrrhiza glabra (GG) (licorice, Fabaceae/Papilionaceae) have a rich ethnobotanical history. The roots are used as a folk medicine both in Europe and in Eastern countries. The main components are the triterpene saponins, glycyrrhizin and glycyrrhetic acid, which are believed to be partly responsible for anti-ulcer, anti-inflammatory, anti-diuretic, anti-epileptic antiallergic and antioxidant properties of the plants well as their ability to "fight" low blood pressure [34]. Furthermore, GG extracts have been shown to possess antidepressant-like, memory-enhancing activities and produce antithrombotic effects. On the other hand, the root extracts are reported to exhibit antiangiogenic and antitumor activities and radio-protective effects. Glabridin (an isoflavan) and isoliquiritigenin (aflavonoid), are pharmacologically active compounds of GG.

Glabridin is reported to be a potent antioxidant towards LDL oxidation [35-36], whereas isoliquiritigenin is known to exert vasore-laxant effect, anti-platelet, anti-viral, estrogenic activities and has the protective potential against cerebral ischemic injury [37]. Antihyperlipilaemic and antihyper-triglyceridaemic properties of GG root have also been reported [38]. Maurya et al. [39] also reported the antidyslipidaemic activity of GG. The ethanolic (95\%) extract of root of GG and its fractions were investigated by Santosh et al [40] for its antidyslipidemic activity on HFD induced dyslipidemic hamsters and there was a reduction in LDL-cholesterol level. 


\section{Conclusion}

Hyperlipidemia is related to cardiovascular disorder and obesity. Hypolipidemic drugs are extensively used to prevent such disorders, but these drugs have other adverse effects. However, due to adverse side effects, there is a demand for new compounds for the treatment of hyperlipidemia. The potency of herbal drugs is significant and they have negligible side effects than the synthetic hypolipidemic drugs. Patients demand these natural products due to their hypolipidemic activities. This review acts as a ready reference for the scientific community, in specific to researchers and students looking for sources of knowledge on medicinal plants that leads for new bioactive compounds and develops an increased interest in these medicinal plants.

\section{References}

1. Jain P, Surana SJ (2015) A review of Indian medicinal plants with hypolipidemic activity and their medicinal importance. World Journal of Pharmacy and Pharmaceutical Sciences 4(3): 1477-1493.

2. Edeoga HO, Okwu DE, Mbaebie BO (2005) Phytochemical constituents of some Nigerian medicinal plants. African Journal of Biotechnology 4(7): 685-688.

3. Bauman AE (2004) Updating the evidence that physical activity is good for health: an epidemiological review 2000-2003. Journal of Science and Medicine in Sport 7(1): 6-19.

4. Kaliora AC, Dedoussis GVZ, Schmidt H (2006) Dietary antioxidants in preventing atherogenesis. Atherosclerosis 187(1): 1-17.

5. Seth SD, Sharma B (2004) Medicinal plants of India. Indian Med Res 120(1): 9-11.

6. Berliner JA, Heinecke JW (1996) The role of oxidized lipoproteins in atherogenesis. Free Radical Biology Med 20(5): 707-727.

7. Sivarajan SS, Balchandra A (1994) Ayurvedic Drugs and their Plant Source. Oxford and IBH Publication Company Pvt. Ltd, 176-177.

8. Nadkarni KM, Nadkarni AK (1996) Indian Materica Medica, Vol. I, Popular Prakashan pp. 722-723.

9. Chopra BN, Nayaram SL, Chopra IC (1992) Glossary of Indian Medicinal Plants, Publication and Information Directorate. Council of Scientific and Industrial Research p. 148.

10. Chopra RN, Chopra K, Verma BS (1992) Supplementto the Glossary of Indian Medicinal Plants, Publication and Information Directorate Council of Scientific and Industrial Research p. 51.

11. Trease GE, Evans MC (1983) Textbook of Pharmacognosy, (12 ${ }^{\text {th }}$ edn.). Balliere p. 74-76.

12. Shirwaikar A, Sreenivasan KK (1996) Chemical Investigation and Antihepatotoxic Activity of the Fruits of L. siceraria. Indian J Pharm Sci 58(5): 197-202.

13. Agarwal SS, Mohale DS, Ghule BV, Saoji AN, Yeole PG (2008) studies on the antihyperlipidemic activity of flavonoidal fraction of Lagenaria siceraria. Int J Chem Sci 6(2): 751-760.

14. Ghule BV, Ghante MH, Saoji AN, Yeole PG (2006) Hypolipidemic and antihyperlipidemic effects of Lagenaria siceraria (Mol) fruit extracts. Indian J of Experimental Biology 44(11): 905-909.

15. Nainwal P, Dhamija K, Tripathi S (2011) Study of antihyperlipidemic effect on the juice of the fresh fruits of Lagenaria siceraria. Int J of Pharmacy and Pharmaceutical Sciences 3(1): 88-90.

16. Mohale DS, Dewani AP, Saoji AN, Khadse (2008) Antihyperlipidemic activity of isolated constituents from the fruits of Lagenaria siceraria in albino rats. Int J of Green Pharmacy pp. 104-107.
17. Rout OP, Acharya R, Mishra SK (2012) Oleogum resin Guggulu: Areview of the medicinal evidence for its therapeutic properties. Int J Res Ayurveda Pharm 3: 15-21.

18. Acharya YT (2003) Sushruta Samhita of Sushruta, Sutra sthana 15/32. Nibandha smgraha Commentary by Dalhanacharya. Varanasi: Chaukhambha Surbharti Prakashan p. 73.

19. Satyavati GV (1966) Effect of an indigenous drug on disorders of lipid metabolism with special reference to atherosclerosis and obesity (Medoroga). MD Ayu Thesis (Doctarate of Ayurvedic Medicine). Varanasi: Banaras Hindu University.

20. Agarwal RC, Singh SP, Saran PK (1986) Clinical trial of guggulipid A new hypolipedemic agent of plant origin in primary Hyperlipidaemia. Indian J Med Res 84: 626.

21. Nityanand S, Shrivastav JS, Asthana OP (1989) Clinical trials with gugulipid A new hyperlipidaemic agent. J Assoc Phys India 37: 323.

22. Satyavati GV (1988) Gum guggul (Commiphora mukul) the success story of an ancient insight leading to a modern discovery. Indian Journal of Medical Research 87(4): 327-335.

23. De Morais SM, Facundo VA, Bertini LM (2007) Chemical composition and larvicidal activity of essential oils from piper species. Biochemical Systematics and Ecology 35(10): 670-675.

24. Sahni CA, Hepfinger, Sauer KA (2005) Guggulipiduse in hyperlipidemia: case report and review of the literature. American Journal of HealthSystem Pharmacy 62(16): 690-1692.

25. Nityanand S, Srivastava JS, Asthana OP (1989) Clinical trials with gugulipid-a new hypolipidaemic agent. The Journal of the Association of Physicians of India 37(5): 323-328.

26. Verma SK, Bordia A (1988) Effect of Commiphora mukul (gum guggulu) in patients of hyperlipidemia with special reference to HDL-cholesterol. Indian Journal of Medical Research 87(4): 356-360.

27. (2007) The Ayurvedic Pharmacopoeia of India (Formulations) Department of Indian Systems of Medicine and Homeopathy, Ministry of Health and Family Welfare, Government of India, New Delhi, India, (1 $1^{\text {st }}$ edn.).

28. Baldwa V, Bhasin V, Ranka P, Mathur K (1981) Effects of Commiphora mukul (guggulu) in experimentally induced hyperlipemia andatherosclerosis. The Journal of the Association of Physicians of India 29(1): 13-17

29. Hasani RS, Nayebi N, Moradi L, Mehri A, Larijani B, Abdollahi M (2010) The efficacy and safety of herbal medicines used in the treatment of hyperlipidemia; a systematic review. Current Pharmaceutical Design 16(26): 2935-2947.

30. Panda S, Kar A (1999) Gugulu (Commiphora mukul) induces triiodothyronine production: possible involvement of lipid peroxidation. Life Sciences 65(12): 137-141.

31. Wang X, Greilberger J, Ledinski G, Kager G, Paigen B, Urgens GJ (2004) The hypolipidemic natural product Commiphora mukul and its component guggulsterone inhibit oxidative modification of LDL. Atherosclerosis 172(2): 239-246

32. Chander R, Khama AK, Kapoor NK (1996) Lipid Lowering Activity of Guggulsterone from Commiphora mukul in Hyperlipaemic Rats. Phytotherapy Research 10: 508-511.

33. Chander R, Khama AK, Kapoor NK (1996) Lipid Lowering Activity of Guggulsterone from Commiphora mukul in Hyperlipaemic Rats. Phytotherapy Research 10: 508-511.

34. Ross IA (2001) Medicinal plants of the world. Totowa, Humana Press Inc, USA.

35. Vaya J, Belinky PA, Aviram M (1997) Antioxidant Constituents from Licorice Roots: Isolation, Structure Elucidation and Antioxidative Capacity toward LDL Oxidation. Free Radical Biol Med 23(2): 302-313. 
36. Belinky PA, Aviram M, Fuhrman B, Rosenblat M, Vaya J (1998) The antioxidative effects of the isoflavan glabridin on endogenous constituents of LDL during its oxidation. Atherosclerosis 137(1): 49-61.

37. Zhan C, Yang J (2006) Protective effects of isoliquiritigenin in transient middle cerebral artery occlusion-induced focal cerebral ischemia in rats. Pharmacol Res 53(3): 303-309.

38. Sitohy MZ, El-Massry RA, El-Saadany SS, Labib SM (1991) Metabolic effects of licorice roots (Glycyrrhiza glabra) on lipid distribution pattern, liver and renal functions of albino rats. MS Nahrung 35(8): 799-806.

\section{ISSN: 2574-1241}

DOI: $10.26717 / B J S T R .2018 .09 .001738$

Reema Srivastava. Biomed J Sci \& Tech Res

(C) This work is licensed under Creative

Submission Link: https://biomedres.us/submit-manuscript.php
39. Maurya SK, Raj K, Srivastava AK (2009) Antidyslipidemic activity of Glycyrrhiza Glabra in high fructose diet induced dyslipidaemic Syrian golden hamsters. Indian J of Clinical Biochemistry 24(4): 404-409.

40. Santosh KM, Kanwal R, Arvind KS (2009) Antidyslipidaemic activity of Glycyrrhiza glabra in high fructose diet induced dsyslipidaemic Syrian golden hamsters. Indian Journal of Clinical Biochemistry 24(4): 404409 .

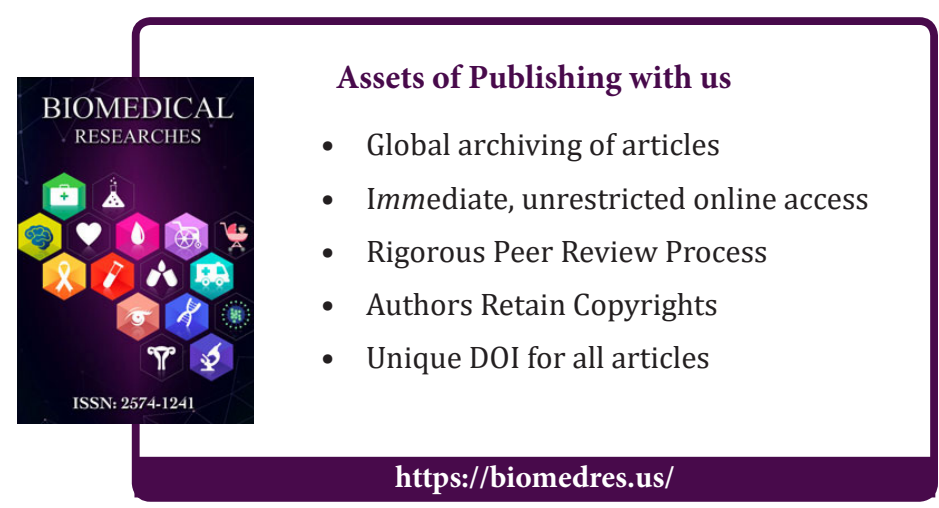

